Article

\title{
Carbon Molecular Sieve Membranes Comprising Graphene Oxides and Porous Carbon for $\mathrm{CO}_{2} / \mathrm{N}_{2}$ Separation
}

\author{
Chong Yang Chuah ${ }^{1}\left(\mathbb{D}\right.$, Junghyun Lee ${ }^{2}$, Juha Song ${ }^{2}$ and Tae-Hyun Bae ${ }^{3, *(D)}$ \\ 1 Singapore Membrane Technology Centre, Nanyang Environment and Water Research Institute, \\ Nanyang Technological University, Singapore 637141, Singapore; chongyang.chuah@ntu.edu.sg \\ 2 School of Chemical and Biomedical Engineering, Nanyang Technological University, \\ Singapore 637459, Singapore; junghyun002@e.ntu.edu.sg (J.L.); songjuha@ntu.edu.sg (J.S.) \\ 3 Department of Chemical and Biomolecular Engineering, Korea Advanced Institute of Science and Technology, \\ Daejeon 34141, Korea \\ * Correspondence: thbae@kaist.ac.kr
}

Citation: Chuah, C.Y.; Lee, J.; Song,

J.; Bae, T.-H. Carbon Molecular Sieve Membranes Comprising Graphene Oxides and Porous Carbon for $\mathrm{CO}_{2} / \mathrm{N}_{2}$ Separation. Membranes 2021, 11, 284. https://doi.org/10.3390/ membranes 11040284

Academic Editor: Adolfo Iulianelli

Received: 24 March 2021

Accepted: 9 April 2021

Published: 12 April 2021

Publisher's Note: MDPI stays neutral with regard to jurisdictional claims in published maps and institutional affiliations.

Copyright: () 2021 by the authors. Licensee MDPI, Basel, Switzerland. This article is an open access article distributed under the terms and conditions of the Creative Commons Attribution (CC BY) license (https:// creativecommons.org/licenses/by/ $4.0 /)$.
Abstract: To improve the $\mathrm{CO}_{2} / \mathrm{N}_{2}$ separation performance, mixed-matrix carbon molecular sieve membranes (mixed-matrix CMSMs) were fabricated and tested. Two carbon-based fillers, graphene oxide (GO) and activated carbon (YP-50F), were separately incorporated into two polymer precursors (Matrimid ${ }^{\circledR} 5218$ and ODPA-TMPDA), and the resulting CMSMs demonstrated improved $\mathrm{CO}_{2}$ permeability. The improvement afforded by YP-50F was more substantial due to its higher accessible surface area. Based on the gas permeation data and the Robeson plot for $\mathrm{CO}_{2} / \mathrm{N}_{2}$ separation, the performances of the CMSMs containing $15 \mathrm{wt} \% \mathrm{YP}-50 \mathrm{~F}$ and $15 \mathrm{wt} \% \mathrm{GO}$ in the mixed polymer matrix surpassed the 2008 Robeson upper bound of polymeric membranes. Hence, this study demonstrates the feasibility of such membranes in improving the $\mathrm{CO}_{2} / \mathrm{N}_{2}$ separation performance through the appropriate choice of carbon-based filler materials in polymer matrices.

Keywords: graphene oxide; activated carbon; carbon molecular sieve membrane; carbon capture; gas permeation test

\section{Introduction}

Despite efforts to mitigate the dependence on non-renewables through the creation of alternative energy sources, technical challenges such as intermittency and high cost of energy production have hampered their practical usefulness thus far $[1,2]$. Meanwhile, considering the fact that the atmospheric $\mathrm{CO}_{2}$ concentration had surpassed $400 \mathrm{ppm}$ in 2013 [3-5], the release of this potent greenhouse gas into the atmosphere during the combustion process should be minimized. To this end, carbon capture and sequestration (CCS) has been proposed. In post-combustion $\mathrm{CO}_{2}$ capture, typically $70 \%$ of the total cost of CCS operation is derived from the $\mathrm{CO}_{2}$ capture step [6-9]. Therefore, more effective protocols are necessary to capture $\mathrm{CO}_{2}$ at the lowest possible cost. In industrial processes, amine scrubbing, which depends on nucleophilic substitution reaction between amine and $\mathrm{CO}_{2}$, is considered as one of the most reliable CCS technologies $[10,11]$. However, such process remains limited by the high energy penalty. This is associated with the high isosteric heat of adsorption ( -50 to $-100 \mathrm{~kJ} / \mathrm{mol}$ ) at low $\mathrm{CO}_{2}$ loading and the large volume of water in the sorbent [12]. As an alternative, the use of membranes for gas separation is considered a highly feasible approach due to the small plant footprint and high energy efficiency. In principle, polymeric membranes are ideally suited to this technology due to a wellestablished synthesis procedure and the feasibility of developing membranes in various configurations. Nevertheless, a trade-off relationship between permeability and selectivity has been reported, as expressed by the Robeson upper bound [13,14], arising from the fact that gas transport through polymeric membrane occurs via solution-diffusion process. 
Meanwhile, the carbon molecular sieve membrane (CMSM), which is fabricated via carbonization of polymeric precursors, has demonstrated the potential to improve gas separation performances. CMSMs can be prepared by a variety of treatment process (e.g., under an inert gas or in a vacuum) [15-17]. However, their performance is highly dependent on the pyrolysis operating parameters during fabrication and the initial choice of polymer precursors $[18,19]$. Besides, it is worth noting that synthesis of 6FDA-based polyimides and PIM-1, which possess high intrinsic gas permeabilities, typically requires extensive monomer purifications to increase the molecular weight [20]. This hampers the potential large-scale production of these polymers. Meanwhile, the gas separation performance of CMSMs could also be enhanced by the appropriate choice of mixed-matrix membranes with the addition of suitable porous fillers. The mixed-matrix CMSMs fabricated by such a process could be expected to show substantial performance enhancements, with the possibility of overcoming the trade-off relation between permeability and selectivity.

In this study, mixed-matrix CMSMs were fabricated via the incorporation of two different types of carbon-based fillers, which are graphene oxide (GO) and activated carbon (YP-50F) into the polymeric membranes. GO is typically developed from the oxidation of graphene, which is the crystalline allotrope of carbon [21]. On the other hand, activated carbons do not have well-defined crystallinity as these materials are typically produced by the thermal treatment (carbonization) of carbonaceous precursors, including biomass, coal and polymers [6]. Subsequently, the polymer matrices used in this work comprised commercial polyimide (Matrimid ${ }^{\circledR} 5218$ ) and in-house-produced polyimide (ODPATMPDA, where ODPA-4, $4^{\prime}$-oxydiphthalic anhydride, and TMPDA-2,4,6-trimethyl-mphenylenediamine). These polymers were selected due to their reasonably high $\mathrm{CO}_{2}$ permeabilities after being carbonized [15,22]. Meanwhile, in comparison to high freevolume polymers such as 6FDA-based (6FDA-4,4'-(hexafluoroisopropylidene)diphthalic anhydride) polyimides and PIM-1, Matrimid ${ }^{\circledR} 5218$ and ODPA-TMPDA polymers are relatively inexpensive and thus can be produced in a scalable manner. It should be noted that high molecular weight ODPA-TMPDA can be readily synthesized without rigorous monomer purifications [20]. The performance of the synthesized mixed-matrix CMSMs was evaluated by gas permeation tests with a $\mathrm{CO}_{2} / \mathrm{N}_{2}$ mixture as the feed gas to the membrane. The performances were benchmarked against the results reported in the literatures and the Robeson upper bound to quantify the enhancement in the gas separation performance.

\section{Materials and Methods}

\subsection{Materials}

Activated carbon (YP-50F) was purchased from Kuraray Chemical Co. (Tokyo, Japan). Matrimid $^{\circledR} 5218$ polymer was purchased from Huntsman Corporation (Conroe, TX, USA). TMPDA, ODPA, acetic anhydride $\left(\mathrm{Ac}_{2} \mathrm{O}\right)$, graphene oxide $(\mathrm{GO}, 15-20$ sheets, $4-10 \%$ edgeoxidized) and triethylamine (TEA) were purchased from Sigma Aldrich (St. Louis, MO, USA). Chloroform and N,N-dimethylacetamide (DMAc) were purchased from VWR. Distilled water was synthesized in-house. All chemicals and reagents mentioned above were used as received without additional purifications.

\subsection{Synthesis of ODPA-TMPDA Polymer}

The synthesis of ODPA-TMPDA polymer can be summarized by the reaction scheme in Figure 1 [23-25]. First, $20.0 \mathrm{~g}$ of DMAc was poured into a round-bottom flask, following which $1.63 \mathrm{~g}$ of TMPDA was added. During this process, sufficient agitation time was allocated to assure complete dissolution of TMPDA. This was followed by the addition of $3.36 \mathrm{~g}$ of ODPA to the solution. Vigorous stirring for at least $24 \mathrm{~h}$ was performed to create polyamic acid with $20 \mathrm{wt} \%$ concentration. Subsequently, imidization process was performed via the addition of $4.44 \mathrm{~g}$ of $\mathrm{Ac}_{2} \mathrm{O}$ and $4.39 \mathrm{~g}$ of TEA. Agitation for at least $24 \mathrm{~h}$ was conducted, followed by reprecipitation in ethanol solution. The unreacted substituents potentially present in the polymer were removed by washing with copious amount of ethanol. Finally, the polymer was dried in a vacuum oven at $120{ }^{\circ} \mathrm{C}$. The structural 
properties of the as-synthesized ODPA-TMPDA polymer were characterized by Fourier Transform-Infrared Spectroscopy (FT-IR, Shimadzu, Kyoto, Japan) under ambient condition. The measurement was conducted in the wavenumber that ranged from $450-4000 \mathrm{~cm}^{-1}$ at the resolution of $4 \mathrm{~cm}^{-1}$.<smiles>Cc1cc(C)c(N)c(C)c1N</smiles><smiles>O=C1OC(=O)c2cc(Cc3ccc4c(c3)C(=O)OC4=O)ccc21</smiles><smiles>CCN(CC)CC</smiles><smiles>Cc1cc(C)c(N2C(=O)c3ccc(Cc4ccc5c(c4)C(=O)N(C)C5=O)cc3C2=O)c(C)c1NC(C)(C)C</smiles>

Figure 1. Reaction scheme for the synthesis of ODPA-TMPDA polymer.

\subsection{Synthesis of Mixed-Matrix Carbon Molecular Sieve Membrane (Mixed-Matrix CMSM)}

As illustrated in Figure 2, CMSMs were synthesized via the following procedure [22,26]. First, the polymer precursor membrane was prepared in a flat sheet configuration by solution-casting approach. A polymer dope solution was prepared by dissolving Matrimd ${ }^{\circledR}$ 5218 and ODPA-TMPDA powders in chloroform. Then, a mixed-matrix polymer precursor membrane was fabricated by dispersing GO and YP-50F into the solution, using a sonication horn (Q125, Qsonica, Newton, CT, USA) to minimize the potential for particle aggregation. After sonication, the polymer was added to form the dope solution, which was then left agitated for a sufficient period before casting the membrane on a glass plate. The stability of the casting solution was investigated by taking photographic images at $12 \mathrm{~h}$ and $24 \mathrm{~h}$ after stopping agitation (Figure S1). The casting step was performed in a glovebox filled with chloroform vapor to prevent the rapid evaporation of chloroform from the dope solution. The membrane precursors were subsequently annealed in a vacuum oven at $160{ }^{\circ} \mathrm{C}$ overnight to remove any residual solvents present in the membrane. Next, the membrane precursors were carbonized to form CMSMs using a horizontal tube furnace (CTF 12/100/900, Carbolate GERO, Sheffield, United Kingdom). Before commencing the carbonization process, argon gas (99.9995\% purity, Airliquide Singapore, Singapore) was purged throughout the quartz tube to allow the residual air or moisture potentially present in the tube to be removed effectively, for a duration of $1 \mathrm{~h}$. This was followed by a two-step ramp-dwell thermal treatment, comprising heating at a $2{ }^{\circ} \mathrm{C} / \mathrm{min}$ ramp rate from room temperature to $380^{\circ} \mathrm{C}$ (dwelling for $0.5 \mathrm{~h}$ ), followed by heating at a $0.5^{\circ} \mathrm{C} / \mathrm{min}$ ramp rate to $550^{\circ} \mathrm{C}$ (dwelling for $2 \mathrm{~h}$ ). After the thermal treatment, the carbonized membranes were allowed to cool to room temperature via natural convection. The resulting products were the CMSM samples. 


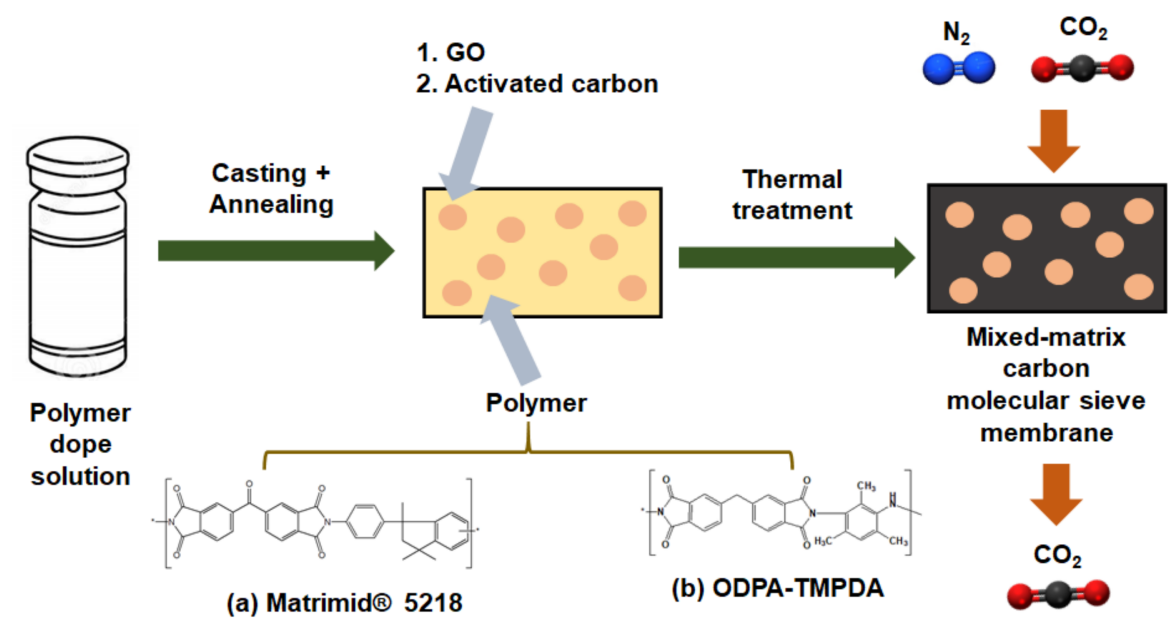

Figure 2. Synthesis scheme for the development of mixed-matrix carbon molecular sieve membranes containing (1) graphene oxide (GO) and (2) activated carbon derived from: (a) Matrimid ${ }^{\circledR} 5218$ and (b) ODPA-TMPDA polymers.

\subsection{Characterizations}

The porosities of the GO and YP-50F were determined using $\mathrm{N}_{2}$ physisorption analysis at $77 \mathrm{~K}$, conducted with the aid of a volumetric gas sorption analyzer (NOVATouch LX2, Quantachrome, Boynton Beach, FL, USA). Prior to the measurement, the samples were outgassed at $250{ }^{\circ} \mathrm{C}$ for $24 \mathrm{~h}$ under high vacuum. Subsequently, the pure component $\mathrm{CO}_{2}$ and $\mathrm{N}_{2}$ adsorption isotherms of GO and YP-50F were measured at $35^{\circ} \mathrm{C}$ (measurement range of $0-1$ bar), during which a water circulator was used to ensure an isothermal environment. Then, the samples were again outgassed at $250{ }^{\circ} \mathrm{C}$ for $24 \mathrm{~h}$ under high vacuum. The resulting gas adsorption isotherms were fitted using the single-site Langmuir equation (Equation (1)), where $q, q_{s a t}, b$ and $p$ are the adsorption quantity (mmol/g), saturation loading (mmol/g), Langmuir constant $\left(\mathrm{bar}^{-1}\right)$ and pressure (bar), respectively. The fitting parameters are summarized in Tables $\mathrm{S} 1$ and $\mathrm{S} 2$. The $\mathrm{CO}_{2} / \mathrm{N}_{2}$ selectivity was calculated using Henry's constant $\left(k_{H}=q_{\text {sat }} b\right)$ and ideal adsorbed solution theory (IAST) as expressed in Equation (2), where $x_{1}$ and $x_{2}$ are the mole fractions of the adsorbed phase, whereas $y_{1}$ and $y_{2}$ are the mole fractions of the gas phase. The micropore size

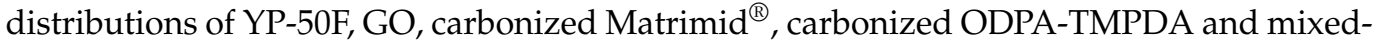
matrix CMSMs were characterized by the measurement of $\mathrm{CO}_{2}$ uptake at $0{ }^{\circ} \mathrm{C}$, with the use of density functional theory. The calculations were performed due to the difficulty in conducting $\mathrm{N}_{2}$ physisorption at $77 \mathrm{~K}$ for carbonized Matrimid ${ }^{\circledR} 5218$ and carbonized ODPA-TMPDA.

$$
\begin{gathered}
q=\frac{q_{\text {sat }} \cdot b_{1} p}{1+b_{1} p} \\
\text { Selectivity }=\frac{x_{1} / x_{2}}{y_{1} / y_{2}}
\end{gathered}
$$

Using the Clausius-Clapeyron equation (Equation (3)), the isosteric heat of adsorption, $-Q_{s t}$ for $\mathrm{CO}_{2}$ and $\mathrm{N}_{2}$, was calculated, where $p$ is the pressure (bar), $T$ is the absolute temperature (Kelvin) and $q$ is the amount adsorbed ( $\mathrm{mmol} / \mathrm{g})$. An explicit analytical solution for the calculation of $-Q_{s t}$ using the single-site Langmuir equation has been reported in the literature [27-29]. Note that $-Q_{s t}$ has been reported to be a weak function of temperature.

$$
-Q_{s t}=R T^{2} \cdot\left(\frac{\partial \ln p}{\partial T}\right)_{q}
$$

Next, the crystallinity of GO and YP-50F was determined using powdered X-ray diffraction (XRD). The diffractor used in this work was equipped with $\mathrm{CuK} \alpha(1.5418 \AA)$ radiation (Bruker, D2 Phaser, MA, USA). Under ambient condition, the diffractograms 
were measured in the $2 \theta$ range of $5^{\circ}-40^{\circ}$, with a step size of $0.02^{\circ}$. The morphologies of GO, YP-50D and the mixed-matrix CMSMs were examined using field-emission scanning electron microscopy (FESEM; Joel, JSM6701, Tokyo, Japan) under an acceleration voltage of $5 \mathrm{kV}$.

\subsection{Gas Permeation Analysis}

A gas permeation system (GTR Tec Corporation) was utilized for the gas permeation tests under constant pressure-variable volume condition. The $\mathrm{CO}_{2} / \mathrm{N}_{2}$ mixture (test gas, $\mathrm{CO}_{2}: 99.8 \%$ purity; $\mathrm{N}_{2}: 99.995 \%$ purity) and helium gas (He: $99.995 \%$ purity) were purchased from Airliquide Singapore. First, the membrane was mounted onto the permeation cell in an isotherm environment at $35^{\circ} \mathrm{C}$. Throughout this process, the test gas and helium gas were supplied continuously at upstream and downstream, respectively, using a mass flow controller to control the flow rate. At a set time interval, the permeated gas was swept by helium, following which the measurement continued until no substantial fluctuation in the concentration of the permeated gas was observed. Then, the concentration of the permeated gas was calculated using gas chromatography. To verify the reproducibility of the gas permeation results, the measurements were conducted for at least three different samples of each CMSM and each mixed-matrix CMSM.

\section{Results}

\subsection{GO and Porous Carbon Fillers}

The surface areas and pore volumes of GO and YP-50F calculated from the $\mathrm{N}_{2}$ physisorption isotherms measured at $77 \mathrm{~K}$ (Figure 3) are summarized in Table 1. For YP-50F, a characteristic Type I isotherm [30] can be observed, indicating a high rate of $\mathrm{N}_{2}$ sorption at low $\mathrm{P} / \mathrm{P}_{\mathrm{O}}$, possibly due to enhanced adsorbent-adsorbate interaction in the narrow micropores. In contrast, GO has a Type III isotherm [30] that shows a lower $\mathrm{N}_{2}$ sorption rate, which can be attributed to its low accessible surface area and micropore volume. The presence of hysteresis between the adsorption and desorption isotherms of both GO and YP-50F indicates mesoporosity, based on the Barrett-Joyner-Halenda analysis, as demonstrated in Figure $3 \mathrm{~b}$. The structures of GO and YP-50F were further characterized by XRD, as shown in Figure S2. The signature peak of GO at c.a. $27^{\circ}$ indicates its low oxidation level (4-10\% edge-oxidized). As a heuristic based on previous studies, the characteristic peak of GO shifts to a lower angle with the increase in the degree of oxidation $[1,3,21,31]$. In contrast, the XRD pattern of YP-50F indicates its amorphous nature. Subsequently, the morphologies of GO and YP-50F were observed using FESEM as shown in Figure 4. Based on the images, it can be concluded that the GO consists of several layers (GO stacks) in platelet form, with the platelet size estimated to be around 1-3 $\mu \mathrm{m}$. Meanwhile, YP-50F is highly irregular with particle sizes ranging from 3 to $6 \mu \mathrm{m}$.
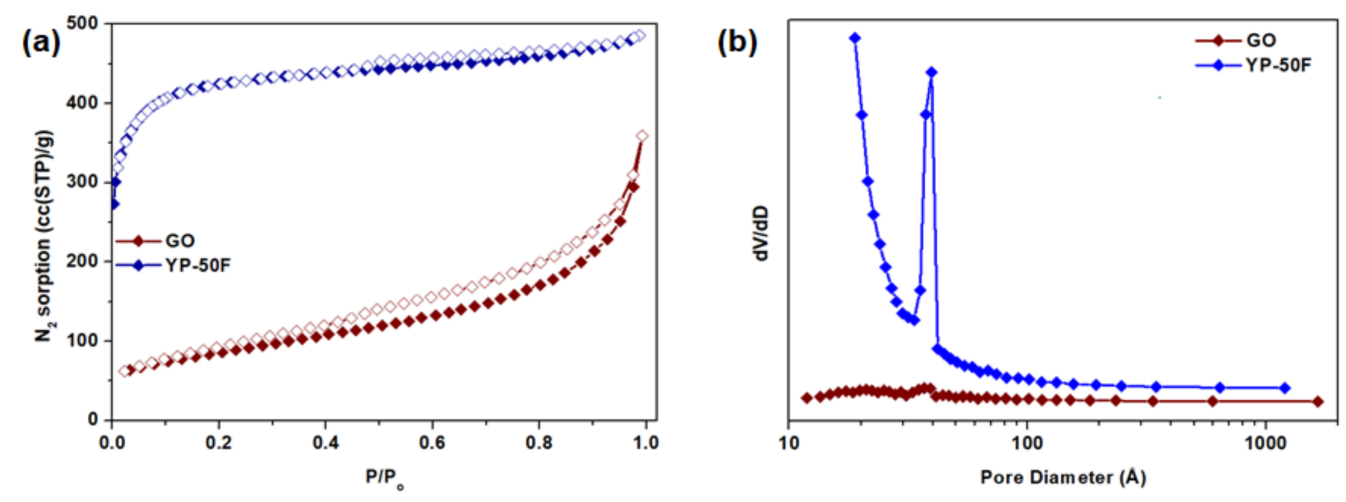

Figure 3. (a) $\mathrm{N}_{2}$ physisorption isotherms and (b) pore size distribution of GO and YP-50F at $77 \mathrm{~K}$. 
Table 1. Surface areas and pore volumes of (graphene oxide) GO and (activated carbon) YP-50F determined by $\mathrm{N}_{2}$ physisorption at $77 \mathrm{~K}$.

\begin{tabular}{|c|c|c|c|c|c|}
\hline Sample & $\mathrm{S}_{\mathrm{BET}}{ }^{1}\left(\mathrm{~m}^{2} / \mathrm{g}\right)$ & $\mathrm{S}_{\mathrm{LANG}}{ }^{1}\left(\mathrm{~m}^{2} / \mathrm{g}\right)$ & $\mathrm{S}_{\text {micro }}{ }^{2}\left(\mathrm{~m}^{2} / \mathrm{g}\right)$ & $\mathrm{V}_{\text {micro }}{ }^{2}\left(\mathrm{cc}^{2} / \mathrm{g}\right)$ & $\mathrm{V}_{\text {total }}{ }^{3}(\mathrm{cc} / \mathrm{g})$ \\
\hline GO & 303 & 414 & 87 & 0.044 & 0.555 \\
\hline YP-50F & 1462 & 1925 & 1377 & 0.632 & 0.987 \\
\hline
\end{tabular}

${ }^{1}$ Surface area (BET and Langmuir) were evaluated in the pressure range, $\mathrm{P} / \mathrm{P}_{\mathrm{o}}=0.05-0.2 .{ }^{2}$ Micropore properties (volume and surface area) were evaluated in the pressure range, $\mathrm{P} / \mathrm{P}_{\mathrm{o}}=0.4-0.6$ using the $t$-plot method. ${ }^{3}$ The total pore volume was determined in the pressure $\mathrm{P} / \mathrm{P}_{\mathrm{o}}=0.99$.
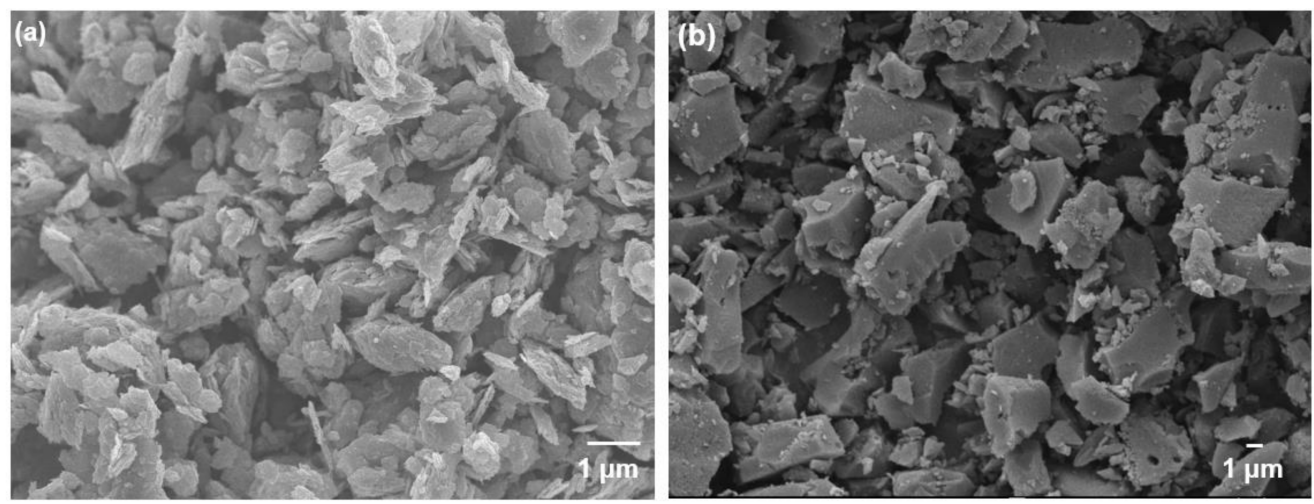

Figure 4. Field-emission scanning electron microscopy (FESEM) images of (a) GO and (b) YP-50F.

\section{2. $\mathrm{CO}_{2}$ and $\mathrm{N}_{2}$ Adsorption Properties of $\mathrm{GO}$ and $\mathrm{YP}-50 \mathrm{~F}$}

The $\mathrm{CO}_{2}$ and $\mathrm{N}_{2}$ adsorption isotherms of $\mathrm{GO}$ and $\mathrm{YP}-50 \mathrm{~F}$ measured at $35^{\circ} \mathrm{C}$ under the pressure range of $0-1$ bar are plotted in Figure 5. The isosteric heat of adsorption $\left(-Q_{s t}\right)$ values of $\mathrm{CO}_{2}$ and $\mathrm{N}_{2}$ that were calculated based on the measurements at two different temperatures $\left(25\right.$ and $\left.35^{\circ} \mathrm{C}\right)$ are summarized in Figure S3a, while the isotherms measured at $25^{\circ} \mathrm{C}$ are included as supplementary information in Figure S3. Comparison of the $\mathrm{CO}_{2}$ and $\mathrm{N}_{2}$ adsorption isotherms reveals that both of the adsorbents demonstrate preferential adsorption of $\mathrm{CO}_{2}$ over $\mathrm{N}_{2}$, presumably due to its higher polarizability $\left(\mathrm{CO}_{2}: 29.1 \times 10^{-25} \mathrm{~cm}^{3}\right.$; $\left.\mathrm{N}_{2}: 17.4 \times 10^{-25} \mathrm{~cm}^{3}\right)$ [32] and quadrupole moment $\left(\mathrm{CO}_{2}: 4.3 \times 10^{-26} \mathrm{esu} \mathrm{cm} \mathrm{cm}^{2} ; \mathrm{N}_{2}\right.$ : $1.5 \times 10^{-26} \mathrm{esu} \mathrm{cm}^{2}$ ) [32]. The isotherms also indicate that YP-50F possesses higher $\mathrm{CO}_{2}$ and $\mathrm{N}_{2}$ adsorption capacities throughout the tested pressure range, which can be attributed to YP-50F possessing a higher surface area and micropore volume than GO. However, the $\mathrm{CO}_{2}$ adsorption profiles of both adsorbents are linear, which indicates the absence of strong binding sites, as depicted by the $-Q_{\text {st }}$ calculation (Figure S4a). The $\mathrm{CO}_{2} / \mathrm{N}_{2}$ selectivity values calculated from IAST are relatively modest, being 21 and 9 for GO and YP-50F (Figure S4b), respectively (with a 1 bar $\mathrm{CO}_{2} / \mathrm{N}_{2}$ feed mixture of 20/80), in comparison to other reported porous materials such as zeolites and metal-organic frameworks (MOFs).
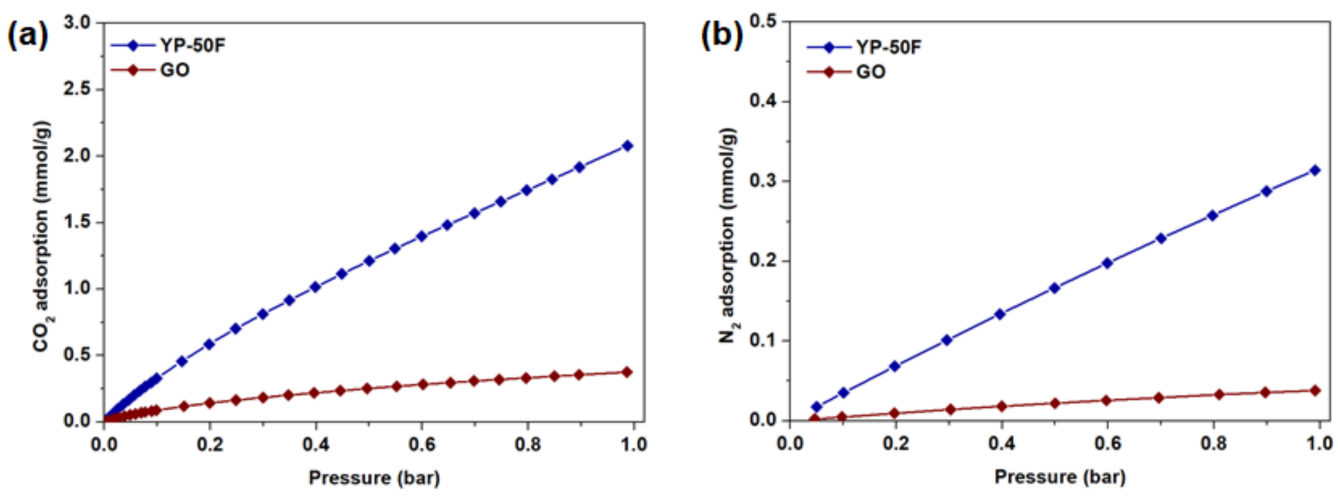

Figure 5. (a) $\mathrm{CO}_{2}$ and (b) $\mathrm{N}_{2}$ adsorption isotherms of $\mathrm{GO}$ and $\mathrm{YP}-50 \mathrm{~F}$ at $35^{\circ} \mathrm{C}$. 


\subsection{Fabrication of Mixed-Matrix CMSM with the Incorporation of GO and YP-50F}

To confirm the successful synthesis of polyimide, the functional groups of ODPATMPDA were characterized by FT-IR analysis (Figure S5). From the FT-IR spectrum, the presence of $\mathrm{C}=\mathrm{O}$ stretching in both symmetric and asymmetric form can be identified from the peaks at $1700 \mathrm{~cm}^{-1}$ and $1800 \mathrm{~cm}^{-1}$, respectively. The peak at $1300 \mathrm{~cm}^{-1}$ indicates C-N stretching. However, no peak at $3500 \mathrm{~cm}^{-1}$, which would correspond to the presence of residual polyamic acid, was observed in this polymer. The synthesis of ODPA-TMPDA involves a two-step procedure. Polyamic acid is first formed by the addition of its two monomers, which is subsequently followed by imidization. Thus, this FT-IR analysis confirmed that the potentially unreacted polyamic acid that could have been present in the polymer had been removed successfully after washing with copious ethanol. Note that our results are consistent to the observation in many previous studies $[10,23,33]$.

The synthesis of mixed-matrix CMSM was conducted at a pyrolysis temperature of $550{ }^{\circ} \mathrm{C}$. Thus, it was necessary to verify the thermal stability of the studied porous materials. As an initial step, thermogravimetric analysis (TGA) was conducted across the temperature range of $40-800{ }^{\circ} \mathrm{C}$ under pure nitrogen purging (Figure S6). Based on the TGA profiles, GO and YP-50F are thermally stable up to approximately $550{ }^{\circ} \mathrm{C}$ and $600{ }^{\circ} \mathrm{C}$, which was sufficient for the development of the mixed-matrix CMSMs in this work. It should be noted that several well-reported porous materials, such as MOFs, generally suffer from poor thermal stability (loss of crystallinity at high temperature), making them infeasible for use in this study $[6,12]$. The initial decrease in the mass of GO and YP-50F is possibly attributable to the removal of residual water or solvents. The presence of adsorbents remaining after the carbonization process was investigated by the XRD measurement of GO (a crystalline material). In the profile (Figure 6), the characteristic peak of GO at $2 \theta=27^{\circ}$ can be detected, indicating that the crystallinity was not lost during the carbonization process (by comparing with the XRD pattern in Figure S2). Therefore, systematic increase in the loading of GO and YP-50F ( $5 \mathrm{wt} \%, 10 \mathrm{wt} \%$ and $15 \mathrm{wt} \%$ ) was conducted in both the carbonized Matrimid ${ }^{\circledR} 5218$ and ODPA-TMPDA membranes.
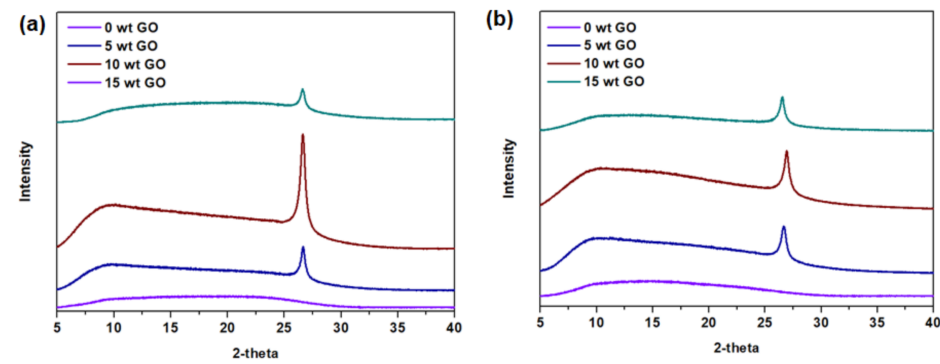

Figure 6. X-ray diffraction patterns of mixed-matrix CMSMs derived from (a) Matrimid ${ }^{\circledR} 5218$ and (b) ODPA-TMPDA membranes with systematic increase in GO loading.

Subsequently, the cross-sectional morphologies of the mixed-matrix CMSMs with the addition of GO and YP-50F were studied by FESEM (Figure 7). It has been reported that inorganic-based adsorbents such as zeolites incorporated into typical mixed-matrix configurations generally do not achieve good compatibility or interfacial adhesion due to the pervasive "sieve-in-a-cage" phenomenon [34-37], which was further verified by taking SEM images at a higher magnification (Figure S7). In this study, however, the carbon-based materials (GO and YP-50F) did not evidently suffer such poor compatibility, as no visible voids were observed in the FESEM images. This may be attributable to the compatible functionalities between the polymer matrices and the carbon-based materials and to the thermal rearrangement of the polymer matrices during the carbonization process, which possibly healed any interfacial defects in the membrane [15,38]. 

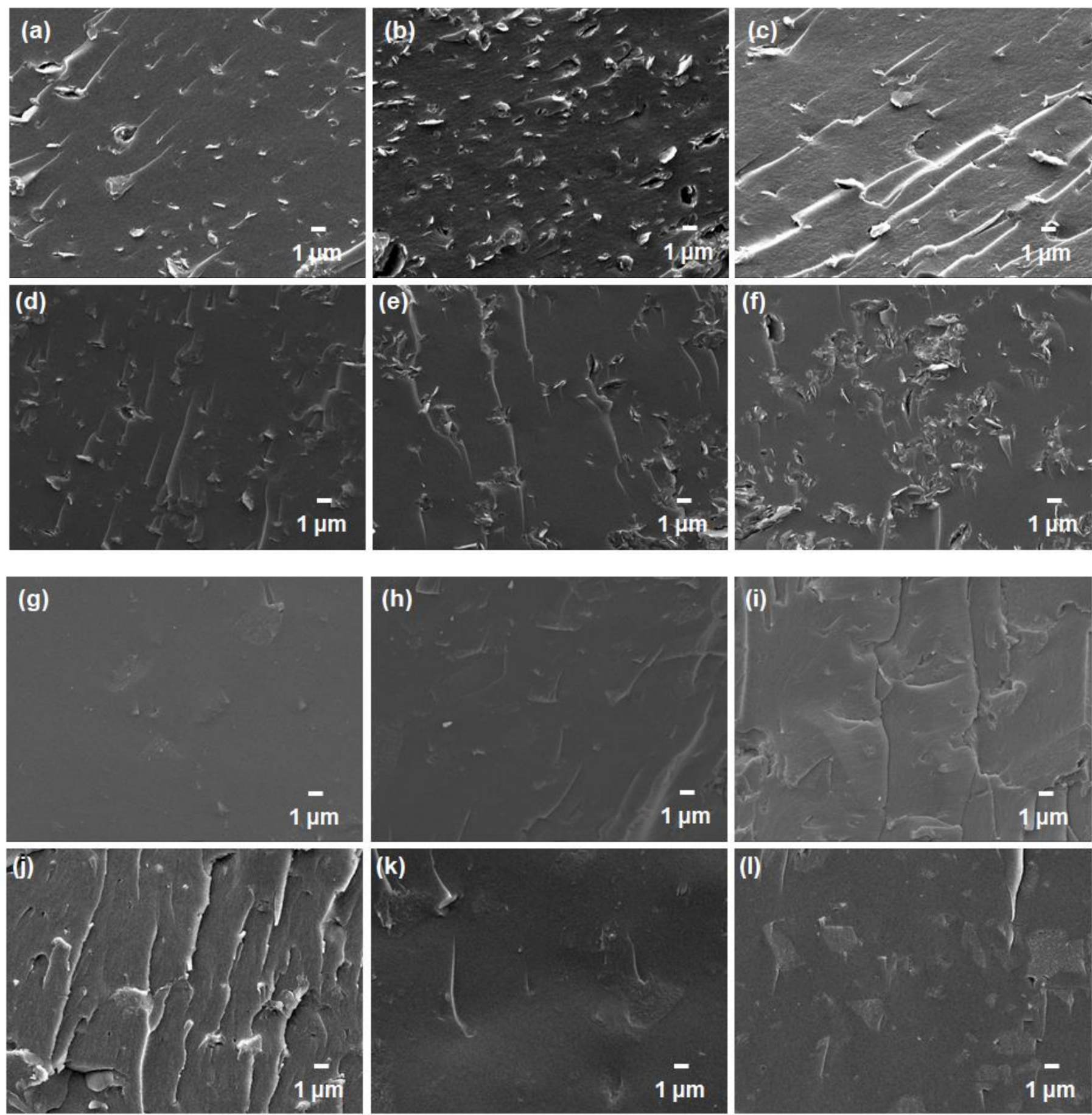

Figure 7. FESEM images of the mixed-matrix carbon molecular sieve membranes containing: (a) $5 \mathrm{wt} \%$; (b) $10 \mathrm{wt} \%$ and (c) $15 \mathrm{wt} \%$ GO in Matrimid ${ }^{\circledR}$ 5218; (d) $5 \mathrm{wt} \%$; (e) $10 \mathrm{wt} \%$ and (f) $15 \mathrm{wt} \%$ GO in ODPA-TMPDA; (g) $5 \mathrm{wt} \%$; (h) $10 \mathrm{wt} \%$ and (i) $15 \mathrm{wt} \%$ YP-50F in Matrimid ${ }^{\circledR} 5218$; (j) $5 \mathrm{wt} \%$; (k) $10 \mathrm{wt} \%$ and (l) $15 \mathrm{wt} \%$ YP-50F in ODPA-TMPDA.

\subsection{Gas Permeation Properties}

The gas permeation properties of the mixed-matrix CMSMs were measured under 1 bar feed pressure $\left(\mathrm{CO}_{2} / \mathrm{N}_{2}: 20 / 80\right)$ at $35{ }^{\circ} \mathrm{C}$, and the results are summarized in Figure 8a,b. Based on the gas permeation data, the CMSMs derived from Matrimid ${ }^{\circledR} 5218$ and ODPA-TMPDA demonstrated an increase in $\mathrm{CO}_{2}$ permeability relative to their precursors reported in the literature [33]. Such enhancement has been reported in many previous studies, where carbonization increases the fractional free volume of membranes due to 
thermal rearrangement $[15,26,38]$. The gas separation performances of the mixed-matrix CMSMs were measured with incremental increases in the loading of GO and YP-50F in the respective membranes. Based on the gas permeation data, all the adsorbents showed substantially greater $\mathrm{CO}_{2}$ permeability than the pure CMSM, with improvement of $110 \%$, $36 \%, 202 \%$ and $64 \%$ for $15 \mathrm{wt} \%$ GO and $15 \mathrm{wt} \%$ YP-50F in carbonized Matrimid ${ }^{\circledR} 5218$ and carbonized ODPA-TMPDA membranes, respectively. Moreover, none of the mixed-matrix CMSMs suffered from a major loss of $\mathrm{CO}_{2} / \mathrm{N}_{2}$ selectivity. The selectivity changes of the CMSMs containing $15 \mathrm{wt} \%$ GO and $15 \mathrm{wt} \%$ YP-50F in carbonized Matrimid ${ }^{\circledR} 5218$ and carbonized ODPA-TMPDA, relative to the pure CMSM, were $1 \%,-16 \%, 38 \%$ and $52 \%$, respectively. Such enhancement can be possibly explained with the aid of micropore size distribution as reported in Figure 8c,d (in which the profiles were calculated from $\mathrm{CO}_{2}$ adsorption at $0{ }^{\circ} \mathrm{C}$ as reported in Figure S8). In general, the presence of additional micropores that are smaller than the pores in pure CMSM potentially contributes to an improved $\mathrm{CO}_{2} / \mathrm{N}_{2}$ selectivity $[39,40]$. Indeed, the presence of the smaller micropores was observed in the pore size distribution of mixed-matrix CMSMs (Figure S9). However, as larger pores (>8 Å) were also observed in both fillers (YP-50F and GO) and mixed-matrix CMSMs, the capability of YP-50F and GO in improving $\mathrm{CO}_{2}$ permeability can be foreseen. Hence, based on the gas permeation results, it can be expected that the incorporation of carbon-based fillers of high porosity is a feasible method to assist the rapid transport of gas molecules through gas separation membranes, leading to an enhancement in gas permeability.
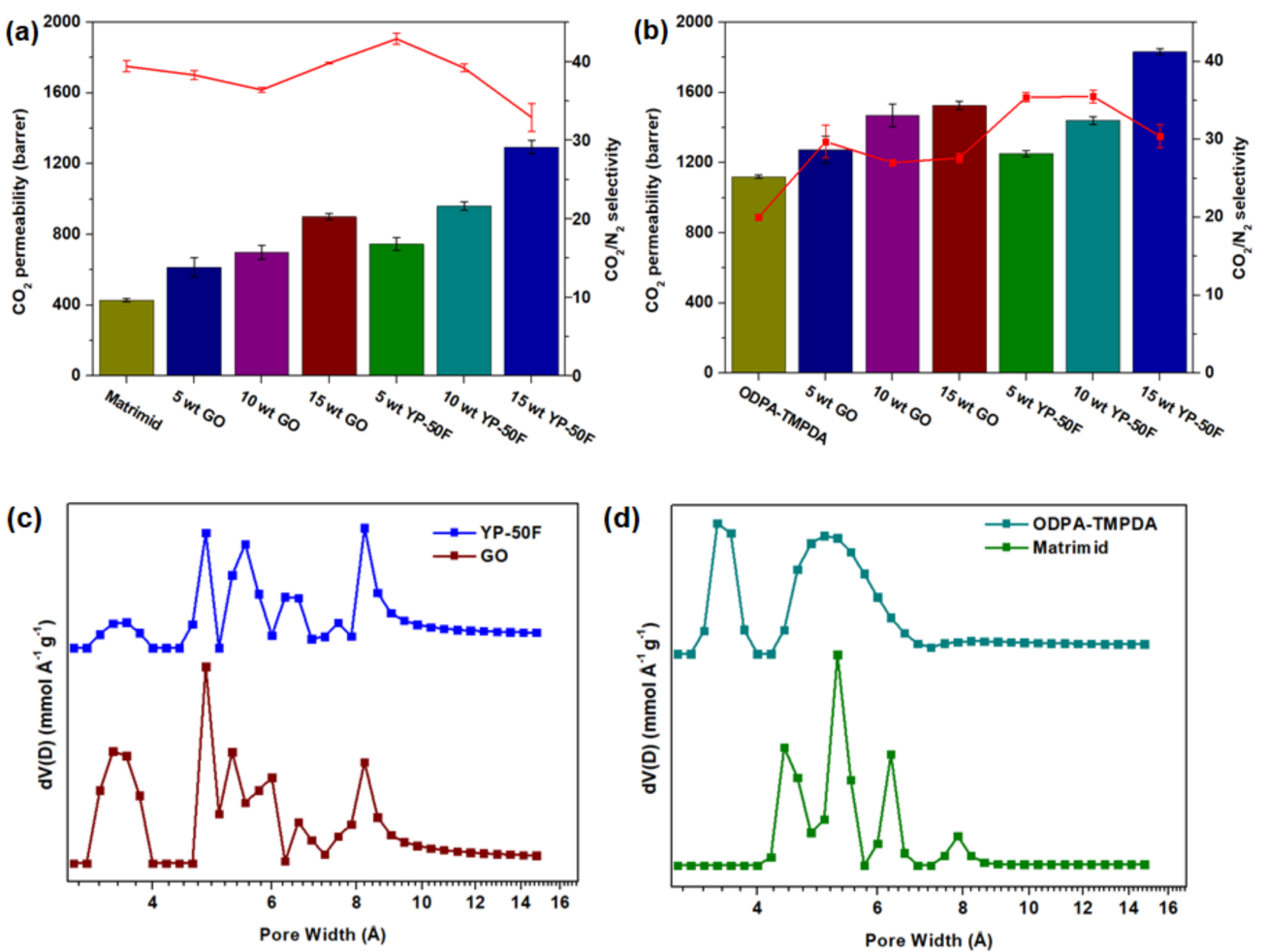

Figure 8. Gas permeation properties of GO- and YP-50F-based mixed-matrix CMSMs for $\mathrm{CO}_{2} / \mathrm{N}_{2}$ separation. The bar graphs indicate $\mathrm{CO}_{2}$ permeability, whereas the line graphs indicate $\mathrm{CO}_{2} / \mathrm{N}_{2}$ selectivity. (a) shows the results for membranes with Matrimid ${ }^{\circledR} 5218$ as the polymer precursor, whereas (b) shows the results for membranes with ODPA-TMPDA as the polymer precursor; (c) micropore size distribution of YP-50F and GO; (d) micropore size distribution of CMSMs (ODPA-TMPDA and Matrimid $\left.{ }^{\circledR}\right)$.

The performances of the mixed-matrix CMSMs were further benchmarked against the Robeson upper bound for $\mathrm{CO}_{2} / \mathrm{N}_{2}$ separation [13] and the available literature data for CMSMs and mixed-matrix CMSMs. The data are summarized in Figure 9 and Figure S10, 
respectively, with the tabulated data given in Tables S3 and S4. Based on the plots, the performance of the mixed-matrix CMSMs in this work surpassed the upper bound. The performance of the CMSMs in this work was far better than that of most CMSMs and mixedmatrix CMSMs reported to date. Thus, the composition of these CMSMs can be considered highly conducive to improving the gas separation performance of polymer membranes.
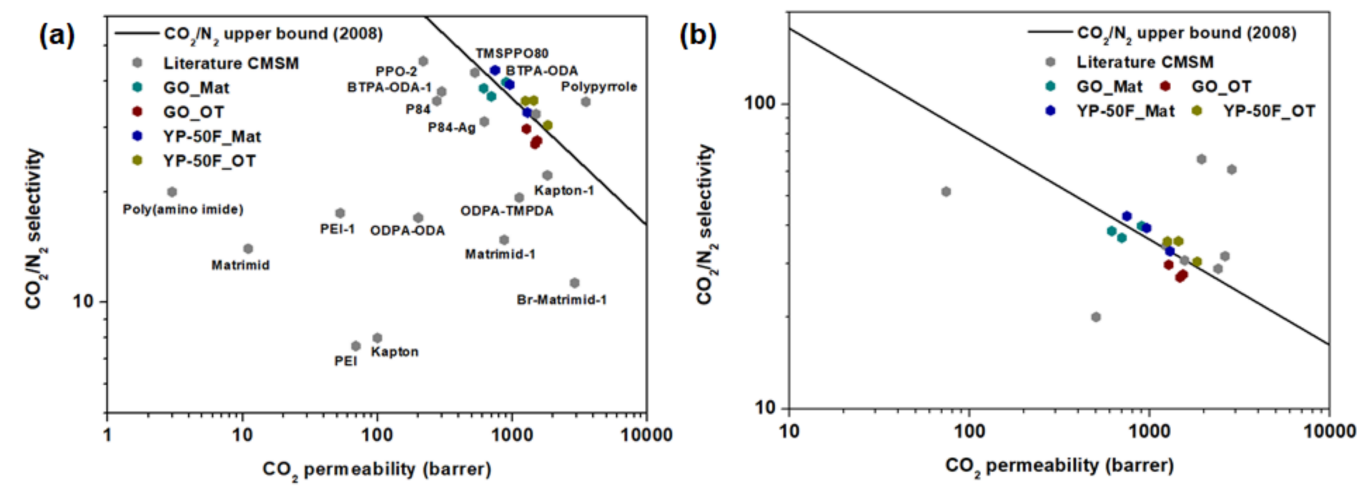

Figure 9. Robeson plot illustrating the performance of the proposed mixed-matrix CMSMs with reference to the literature data for (a) CMSMs [41-50] and (b) mixed-matrix CMSMs [51-53] (summarized in Table S3 and S4, respectively).

\section{Conclusions}

In this work, mixed-matrix CMSMs that contained YP-50F and GO in Matrimid ${ }^{\circledR} 5218$ and ODPA-TMPDA membranes were fabricated for investigation of their potential use in $\mathrm{CO}_{2} / \mathrm{N}_{2}$ separation. Based on the gas permeation data, both YP-50F and GO enhanced the $\mathrm{CO}_{2}$ permeability of the membranes substantially, as compared with the pure CMSM. In particular, for carbonized ODPA-TMPDA, enhancement in both $\mathrm{CO}_{2}$ permeability and $\mathrm{CO}_{2} / \mathrm{N}_{2}$ selectivity were achieved. This is attributed to the smaller micropore size in YP-50F and GO, which allowed enhancement in $\mathrm{CO}_{2} / \mathrm{N}_{2}$ selectivity, as well as the large pore volume, which allowed an improvement in $\mathrm{CO}_{2}$ permeability. Moreover, the performance of our mixed-matrix CMSMs surpassed the 2008 Robeson upper bound for $\mathrm{CO}_{2} / \mathrm{N}_{2}$ separation, indicating that membranes of this composition demonstrate strong improvement in gas separation performance.

Supplementary Materials: The following are available online at https: / www.mdpi.com/article/ 10.3390/membranes11040284/s1, Figure S1: Photographic images upon the incorporation of GO (left) and YP-50F (right) onto Matrimid ${ }^{\circledR} 5218$ (left) and ODPA-TMPDA (right) dope solution. The durations at which the photos were taken are: (a) $12 \mathrm{~h}$ and (b) $24 \mathrm{~h}$, respectively, Figure S2: XRD of GO and YP-50F, Figure S3: $(\mathbf{a}, \mathbf{b}) \mathrm{CO}_{2}$ and $\mathrm{N}_{2}$ adsorption of $\mathrm{GO}$ and activated carbon (YP-50F) at $25{ }^{\circ} \mathrm{C}$, Figure S4: (a) $-Q_{\text {st }}$ of $\mathrm{CO}_{2}$ and $\mathrm{N}_{2}$ and (b) $\mathrm{CO}_{2} / \mathrm{N}_{2}$ IAST selectivity for GO and YP-50F (ratio of $\mathrm{CO}_{2} / \mathrm{N}_{2}$ in the feed is 20/80), Figure S5: FT-IR of ODPA-TMPDA polymer, Figure S6: TGA analysis of GO and activated carbon (YP-50F), Figure S7: FESEM images of mixed-matrix carbon molecular sieve membranes at higher magnification, that contains: (a) $5 \mathrm{wt} \%$; (b) $10 \mathrm{wt} \%$ and (c) $15 \mathrm{wt} \%$ GO in Matrimid ${ }^{\circledR}$ 5218; (d) $5 \mathrm{wt} \%$; (e) $10 \mathrm{wt} \%$ and (f) $15 \mathrm{wt} \%$ GO in ODPA-TMPDA; (g) $5 \mathrm{wt} \%$; (h) $10 \mathrm{wt} \%$ and (i) $15 \mathrm{wt} \%$ YP-50F in Matrimid ${ }^{\circledR} 5218$; (j) $5 \mathrm{wt} \%$; (k) $10 \mathrm{wt} \%$ and (l) $15 \mathrm{wt} \%$ YP-50F in ODPA-TMPDA, Figure S8: $\mathrm{CO}_{2}$ uptake at $0{ }^{\circ} \mathrm{C}$ for YP-50F, GO, carbonized Matrimid ${ }^{\circledR} 5218$ and carbonized ODPA-TMPDA, Figure S9: Micropore size distribution of CMSMs and mixed-matrix CMSMs with: (a) Matrimid ${ }^{\circledR} 5218$ and (b) ODPA-TMPDA as the polymer precursor. The arrowhead in the figure dictates the presence of smaller micropore size in the mixed-matrix CMSM, Figure S10: Robeson plot that demonstrates $\mathrm{CO}_{2}$ permeabilities and $\mathrm{CO}_{2} / \mathrm{N}_{2}$ selectivity of $\mathrm{CMSMs}$ that are based on: (a) Matrimid ${ }^{\circledR} 5218$ and (b) ODPA-TMPDA polymeric precursors, Table S1: Fitting parameters for $\mathrm{CO}_{2}$ and $\mathrm{N}_{2}$ for $\mathrm{GO}$ and YP-50F at $25^{\circ} \mathrm{C}$, Table S2: Fitting parameters for $\mathrm{CO}_{2}$ and $\mathrm{N}_{2}$ for GO and YP-50F at $35{ }^{\circ} \mathrm{C}$, Table S3: Performance of pure CMSM membranes that have been reported in the literature for $\mathrm{CO}_{2} / \mathrm{N}_{2}$ separation, Table S4: Performance of mixed-matrix CMSM membranes for $\mathrm{CO}_{2} / \mathrm{N}_{2}$ separation. 
Author Contributions: Experimental and characterization, C.Y.C.; assistance in membrane characterization, J.L.; Original draft preparation, C.Y.C.; writing-review and editing, T.-H.B., J.S.; funding acquisition, T.-H.B. All authors have read and agreed to the published version of the manuscript.

Funding: This work is supported by the National Research Foundation of Korea (NRF) grant funded by the Korea government MSIT (Reference number: NRF-2020R1F1A1064853).

Institutional Review Board Statement: Not applicable.

Informed Consent Statement: Not applicable.

Data Availability Statement: Not applicable.

Conflicts of Interest: The authors declare no conflict of interest.

\section{References}

1. Li, W.; Chuah, C.Y.; Yang, Y.; Bae, T.-H. Nanocomposites formed by in situ growth of NiDOBDC nanoparticles on graphene oxide sheets for enhanced $\mathrm{CO}_{2}$ and $\mathrm{H}_{2}$ storage. Microporous Mesoporous Mater. 2018, 265, 35-42. [CrossRef]

2. Pires, J.; Martins, F.; Alvim-Ferraz, M.; Simões, M. Recent developments on carbon capture and storage: An overview. Chem. Eng. Res. Des. 2011, 89, 1446-1460. [CrossRef]

3. Li, W.; Chuah, C.Y.; Nie, L.; Bae, T.-H. Enhanced $\mathrm{CO}_{2} / \mathrm{CH}_{4}$ selectivity and mechanical strength of mixed-matrix membrane in-corporated with NiDOBDC/GO composite. J. Ind. Eng. Chem. 2019, 74, 118-125. [CrossRef]

4. Zhai, P.; Masson-Delmotte, V.; Pörtner, H.O.; Roberts, D.C.; Skea, J.; Shukla, P.R.; Pirani, A.; Moufouma-Okia, W.; Péan, C.; Pidcock, R.; et al. Global warming of $1.5^{\circ} \mathrm{C}$. An IPCC Special Report on the Impacts of Global Warming of $1.5^{\circ} \mathrm{C}$ Above Pre-Industrial Levels And Related Global Greenhouse Gas Emission Pathways, in the Context of Strengthening the Global Response to the Threat of Climate Change, Sustainable Development, and Efforts To Eradicate Poverty; Intergovernmental Panel of Climate Change (IPCC): Geneva, Switzerland, 2019.

5. Zhang, Y.; Sunarso, J.; Liu, S.; Wang, R. Current status and development of membranes for $\mathrm{CO}_{2} / \mathrm{CH}_{4}$ separation: A review. Int. J. Greenh. Gas Control 2013, 12, 84-107. [CrossRef]

6. Chuah, C.Y.; Goh, K.; Yang, Y.; Gong, H.; Li, W.; Karahan, H.E.; Guiver, M.D.; Wang, R.; Bae, T.-H. Harnessing Filler Materials for Enhancing Biogas Separation Membranes. Chem. Rev. 2018, 118, 8655-8769. [CrossRef]

7. Chuah, C.Y.; Kim, K.; Lee, J.; Koh, D.-Y.; Bae, T.-H. $\mathrm{CO}_{2}$ absorption using membrane contactors: Recent progress and future per-spective. Ind. Eng. Chem. Res. 2019, 59, 6773-6794. [CrossRef]

8. Khalilpour, R.; Mumford, K.; Zhai, H.; Abbas, A.; Stevens, G.; Rubin, E.S. Membrane-based carbon capture from flue gas: A review. J. Clean. Prod. 2015, 103, 286-300. [CrossRef]

9. Luis, P.; Van Gerven, T.; Van der Bruggen, B. Recent developments in membrane-based technologies for $\mathrm{CO}_{2}$ capture. Prog. Energy Combust. Sci. 2012, 38, 419-448. [CrossRef]

10. Samarasinghe, S.; Chuah, C.Y.; Li, W.; Sethunga, D.; Wang, R.; Bae, T.-H. Incorporation of CoIII acetylacetonate and SNW-1 nanoparticles to tailor $\mathrm{O}_{2} / \mathrm{N}_{2}$ separation performance of mixed-matrix membrane. Sep. Purif. Technol. 2019, 223, $133-141$. [CrossRef]

11. Rochelle, G.T. Amine Scrubbing for $\mathrm{CO}_{2}$ Capture. Science 2009, 325, 1652-1654. [CrossRef]

12. Sumida, K.; Rogow, D.L.; Mason, J.A.; McDonald, T.M.; Bloch, E.D.; Herm, Z.R.; Bae, T.-H.; Long, J.R. Carbon Dioxide Capture in Metal-Organic Frameworks. Chem. Rev. 2012, 112, 724-781. [CrossRef]

13. Robeson, L.M. The upper bound revisited. J. Membr. Sci. 2008, 320, 390-400. [CrossRef]

14. Robeson, L.M. Correlation of separation factor versus permeability for polymeric membranes. J. Membr. Sci. 1991, 62, 165-185. [CrossRef]

15. Li, W.; Goh, K.; Chuah, C.Y.; Bae, T.-H. Mixed-matrix carbon molecular sieve membranes using hierarchical zeolite: A simple approach towards high $\mathrm{CO}_{2}$ permeability enhancements. J. Membr. Sci. 2019, 588, 117220. [CrossRef]

16. Ismail, A.; David, L. A review on the latest development of carbon membranes for gas separation. J. Membr. Sci. 2001, 193, 1-18. [CrossRef]

17. Morooka, S.; Kusakabe, K. Microporous Inorganic Membranes for Gas Separation. MRS Bull. 1999, 24, 25-29. [CrossRef]

18. Salleh, W.N.W.; Ismail, A.F.; Matsuura, T.; Abdullah, M.S. Precursor Selection and Process Conditions in the Preparation of Carbon Membrane for Gas Separation: A Review. Sep. Purif. Rev. 2011, 40, 261-311. [CrossRef]

19. Salleh, W.; Ismail, A. Effects of carbonization heating rate on $\mathrm{CO}_{2}$ separation of derived carbon membranes. Sep. Purif. Technol. 2012, 88, 174-183. [CrossRef]

20. Chuah, C.Y.; Samarasinghe, S.; Li, W.; Goh, K.; Bae, T.-H. Leveraging Nanocrystal HKUST-1 in Mixed-Matrix Membranes for Ethylene/Ethane Separation. Membranes 2020, 10, 74. [CrossRef]

21. Nie, L.; Chuah, C.Y.; Bae, T.; Lee, J. Graphene-Based Advanced Membrane Applications in Organic Solvent Nanofiltration. Adv. Funct. Mater. 2021, 31, 2006949. [CrossRef]

22. Chuah, C.Y.; Lee, J.; Bao, Y.; Song, J.; Bae, T.-H. High-performance porous carbon-zeolite mixed-matrix membranes for $\mathrm{CO}_{2} / \mathrm{N}_{2}$ separation. J. Membr. Sci. 2021, 622, 119031. [CrossRef] 
23. Samarasinghe, S.; Chuah, C.Y.; Yang, Y.; Bae, T.-H. Tailoring $\mathrm{CO}_{2} / \mathrm{CH}_{4}$ separation properties of mixed-matrix membranes via combined use of two- and three-dimensional metal-organic frameworks. J. Membr. Sci. 2018, 557, 30-37. [CrossRef]

24. Gong, H.; Chuah, C.Y.; Yang, Y.; Bae, T.-H. High performance composite membranes comprising $\mathrm{Zn}\left(\mathrm{pyyrz}_{2}\left(\mathrm{SiF}_{6}\right)\right.$ nanocrystals for $\mathrm{CO}_{2} / \mathrm{CH}_{4}$ separation. J. Ind. Eng. Chem. 2018, 60, 279-285. [CrossRef]

25. Duan, C.; Jie, X.; Liu, D.; Cao, Y.; Yuan, Q. Post-treatment effect on gas separation property of mixed matrix membranes containing metal organic frameworks. J. Membr. Sci. 2014, 466, 92-102. [CrossRef]

26. Li, W.; Chuah, C.Y.; Bae, T.-H. Hierarchical 5A Zeolite-Containing Carbon Molecular Sieve Membranes for $\mathrm{O}_{2} / \mathrm{N}_{2}$ Separation. Membr. J. 2020, 30, 260-268. [CrossRef]

27. Chuah, C.Y.; Lee, Y.; Bae, T.-H. Potential of adsorbents and membranes for $\mathrm{SF}_{6}$ capture and recovery: A review. Chem. Eng. J. 2021, 404, 126577. [CrossRef]

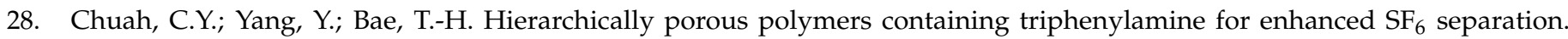
Microporous Mesoporous Mater. 2018, 272, 232-240. [CrossRef]

29. Mason, J.A.; Sumida, K.; Herm, Z.R.; Krishna, R.; Long, J.R. Evaluating metal-organic frameworks for post-combustion carbon dioxide capture via temperature swing adsorption. Energy Environ. Sci. 2011, 4, 3030-3040. [CrossRef]

30. Thommes, M.; Kaneko, K.; Neimark, A.V.; Olivier, J.P.; Rodriguez-Reinoso, F.; Rouquerol, J.; Sing, K.S. Physisorption of gases, with special reference to the evaluation of surface area and pore size distribution (IUPAC Technical Report). Pure Appl. Chem. 2015, 87, 1051-1069. [CrossRef]

31. Krishnamoorthy, K.; Veerapandian, M.; Yun, K.; Kim, S.-J. The chemical and structural analysis of graphene oxide with different degrees of oxidation. Carbon 2013, 53, 38-49. [CrossRef]

32. Li, J.-R.; Kuppler, R.J.; Zhou, H.-C. Selective gas adsorption and separation in metal-organic frameworks. Chem. Soc. Rev. 2009, 38, 1477-1504. [CrossRef]

33. Chuah, C.Y.; Lee, J.; Song, J.; Bae, T.-H. $\mathrm{CO}_{2} / \mathrm{N}_{2}$ Separation Properties of Polyimide-Based Mixed-Matrix Membranes Comprising UiO-66 with Various Functionalities. Membranes 2020, 10, 154. [CrossRef]

34. Goh, P.; Ismail, A.; Sanip, S.; Ng, B.; Aziz, M. Recent advances of inorganic fillers in mixed matrix membrane for gas separation. Sep. Purif. Technol. 2011, 81, 243-264. [CrossRef]

35. Gong, H.; Lee, S.S.; Bae, T.-H. Mixed-matrix membranes containing inorganically surface-modified 5A zeolite for enhanced CO2/CH4 separation. Microporous Mesoporous Mater. 2017, 237, 82-89. [CrossRef]

36. Bae, T.-H.; Liu, J.; Lee, J.S.; Koros, W.J.; Jones, C.W.; Nair, S. Facile High-Yield Solvothermal Deposition of Inorganic Nanostructures on Zeolite Crystals for Mixed Matrix Membrane Fabrication. J. Am. Chem. Soc. 2009, 131, 14662-14663. [CrossRef]

37. Bae, T.-H.; Liu, J.; Thompson, J.A.; Koros, W.J.; Jones, C.W.; Nair, S. Solvothermal deposition and characterization of magnesium hydroxide nanostructures on zeolite crystals. Microporous Mesoporous Mater. 2011, 139, 120-129. [CrossRef]

38. Li, W.; Chuah, C.Y.; Kwon, S.; Goh, K.; Wang, R.; Na, K.; Bae, T.-H. Nanosizing zeolite 5A fillers in mixed-matrix carbon molecular sieve membranes to improve gas separation performance. Chem. Eng. J. Adv. 2020, 2, 100016. [CrossRef]

39. Chrzanowska, A.; Derylo-Marczewska, A.; Wasilewska, M. Mesocellular Silica Foams (MCFs) with Tunable Pore Size as a Support for Lysozyme Immobilization: Adsorption Equilibrium and Kinetics, Biocomposite Properties. Int. J. Mol. Sci. 2020, $21,5479$. [CrossRef]

40. Matsuoka, K.; Yamagishi, Y.; Yamazaki, T.; Setoyama, N.; Tomita, A.; Kyotani, T. Extremely high microporosity and sharp pore size distribution of a large surface area carbon prepared in the nanochannels of zeolite Y. Carbon 2005, 43, 876-879. [CrossRef]

41. Kim, Y.K.; Park, H.B.; Lee, Y.M. Carbon molecular sieve membranes derived from thermally labile polymer containing blend polymers and their gas separation properties. J. Membr. Sci. 2004, 243, 9-17. [CrossRef]

42. Xiao, Y.; Dai, Y.; Chung, T.-S.; Guiver, M.D. Effects of Brominating Matrimid Polyimide on the Physical and Gas Transport Properties of Derived Carbon Membranes. Macromol. 2005, 38, 10042-10049. [CrossRef]

43. Fuertes, A.; Nevskaia, D.; Centeno, T. Carbon composite membranes from Matrimid ${ }^{\circledR}$ and Kapton ${ }^{\circledR}$ polyimides for gas separation. Microporous Mesoporous Mater. 1999, 33, 115-125. [CrossRef]

44. Suda, H.; Haraya, K. Gas Permeation through Micropores of Carbon Molecular Sieve Membranes Derived from Kapton Polyimide. J. Phys. Chem. B 1997, 101, 3988-3994. [CrossRef]

45. Zhang, B.; Wu, Y.; Lu, Y.; Wang, T.; Jian, X.; Qiu, J. Preparation and characterization of carbon and carbon/zeolite membranes from ODPA-ODA type polyetherimide. J. Membr. Sci. 2015, 474, 114-121. [CrossRef]

46. Barsema, J.; Balster, J.; Jordan, V.; Van Der Vegt, N.; Wessling, M. Functionalized Carbon Molecular Sieve membranes containing Ag-nanoclusters. J. Membr. Sci. 2003, 219, 47-57. [CrossRef]

47. Itta, A.K.; Tseng, H.-H.; Wey, M.-Y. Effect of dry/wet-phase inversion method on fabricating polyetherimide-derived CMS membrane for $\mathrm{H}_{2} / \mathrm{N}_{2}$ separation. Int. J. Hydrogen Energy 2010, 35, 1650-1658. [CrossRef]

48. Rao, P.S.; Wey, M.-Y.; Tseng, H.-H.; Kumar, I.A.; Weng, T.-H. A comparison of carbon/nanotube molecular sieve membranes with polymer blend carbon molecular sieve membranes for the gas permeation application. Microporous Mesoporous Mater. 2008, 113, 499-510. [CrossRef]

49. Kita, H.; Yoshino, M.; Tanaka, K.; Okamoto, K.-I. Gas permselectivity of carbonized polypyrrolone membrane. Chem. Commun. 1997, 1051-1052. [CrossRef]

50. Yoshimune, M.; Fujiwara, I.; Haraya, K. Carbon molecular sieve membranes derived from trimethylsilyl substituted poly (phe-nylene oxide) for gas separation. Carbon 2007, 45, 553-560. [CrossRef] 
51. Li, L.; Wang, T.; Liu, Q.; Cao, Y.; Qiu, J. A high $\mathrm{CO}_{2}$ permselective mesoporous silica/carbon composite membrane for $\mathrm{CO}_{2}$ sep-aration. Carbon 2012, 50, 5186-5195. [CrossRef]

52. Yin, X.; Wang, J.; Chu, N.; Yang, J.; Lu, J.; Zhang, Y.; Yin, D. Zeolite L/carbon nanocomposite membranes on the porous alumina tubes and their gas separation properties. J. Membr. Sci. 2010, 348, 181-189. [CrossRef]

53. Yin, X.; Chu, N.; Yang, J.; Wang, J.; Li, Z. Thin zeolite T/carbon composite membranes supported on the porous alumina tubes for $\mathrm{CO}_{2}$ separation. Int. J. Greenh. Gas Control 2013, 15, 55-64. [CrossRef] 